\title{
Perinatal exposure to methoxychlor enhances adult cognitive responses and hippocampal neurogenesis in mice
}

\author{
Mariangela Martini ${ }^{1}$, Ludovic Calandreau ${ }^{1}$, Mélanie Jouhanneau ${ }^{1}$, Sakina Mhaouty-Kodja ${ }^{2}$ and \\ Matthieu Keller ${ }^{1 *}$ \\ ' Physiologie de la Reproduction et des Comportements, UMR 7247 INRA/CNRS/Université Francois Rabelais, Nouzilly, France \\ 2 Physiopathologie des Maladies du Système Nerveux Central, UMR 7224 CNRS/INSERM U 952/Université Pierre et Marie Curie, Paris, France
}

Edited by:

Valérie Doyère, CNRS, France

Reviewed by:

Aline Desmedt, Université

Bordeaux 1, France

Paola Palanza, University of Parma Italy

*Correspondence:

Matthieu Keller, Physiologie de la Reproduction et des

Comportements, UMR 7247

INRA/CNRS/Université Francois

Rabelais, Centre INRA Val-de-Loire,

37380 Nouzilly, France

e-mail: mkeller@tours.inra.fr
During perinatal life, sex steroids, such as estradiol, have marked effects on the development and function of the nervous system. Environmental estrogens or xenoestrogens are man-made chemicals, which animal and human population encounter in the environment and which are able to disrupt the functioning of the endocrine system. Scientific interest in the effects of exposure to xenoestrogens has focused more on fertility and reproductive behaviors, while the effects on cognitive behaviors have received less attention. Therefore, the present study explored whether the organochlorine insecticide Methoxychlor (MXC), with known xenoestrogens properties, administered during the perinatal period (from gestational day 11 to postnatal day 8 ) to pregnant-lactating females, at an environmentally relevant dose $(20 \mu \mathrm{g} / \mathrm{kg}$ (body weight)/day), would also affect learning and memory functions depending on the hippocampus of male and female offspring mice in adulthood. When tested in adulthood, MXC perinatal exposure led to an increase in anxiety-like behavior and in short-term spatial working memory in both sexes. Emotional learning was also assessed using a contextual fear paradigm and MXC treated male and female mice showed an enhanced freezing behavior compared to controls. These results were correlated with an increased survival of adult generated cells in the adult hippocampus. In conclusion, our results show that perinatal exposure to an environmentally relevant dose of MXC has an organizational effect on hippocampus-dependent memory and emotional behaviors.

Keywords: endocrine disruptor, learning and memory, anxiety, methoxychlor, hormones

\section{INTRODUCTION}

During perinatal life, sex steroids, such as estradiol, have marked effects on the development of the neuroendocrine system and the expression of related behaviors. Indeed, the classical theory of brain sexual differentiation holds that endogenous steroid hormones, during critical periods of development, organize sexual dimorphisms in brain neuronal circuits; these effects are therefore classified as "organizational effect". Once in adulthood, endogenous steroid hormones then act on these sexually dimorphic neural circuits to give rise to sex differences in behavioral responses (which are classified as "activational effects").

A variety of man-made chemicals, which animal and human population encounter daily in their environment, are able to disrupt the functioning of the endocrine system. Certain of these artificial environmental contaminants are called "xenoestrogens", since they mimic the action of naturally produced estrogens (for recent reviews see Frye et al., 2012; Fisher, 2004).

Methoxychlor (MXC) is an organochlorine insecticide that was used to replace Dichlorodiphenyltrichloroethane (DDT) in
1972, due to the adverse effects of DDT on human and wildlife health. MXC was banned in the European Union in $2002^{1}$ and U.S.A. in $2003,{ }^{2}$ but it is a persistent chemical and is still found in the environment (Bempah and Donkor, 2011). Moreover, organochlorine pesticides continue to be used for applications such as mosquito and malaria control in developing countries (World Health Organization, 2011) and measurable amounts of MXC and its metabolites can still be found in human tissues, even where the chemical is not used (OSPAR Commission, 2002). In addition, even if the usage of MXC has ceased in the United States and Europe, exposures may still occur via fruits and vegetables imported to U.S. and European markets from other countries that continue to use MXC. Thus, the human health effects of MXC exposure remain an important public health concern.

MXC is an endocrine disrupting chemical (EDC) belonging to the category of xenoestrogens, which acts as an estrogen receptor

\footnotetext{
${ }^{1}$ http://ec.europa.eu/sanco_pesticides/public/index.cfm?event=activesubstance. selection\& $\mathrm{a}=1$

${ }^{2} \mathrm{http} / / /$ www.epa.gov/oppsrrd1/REDs/methoxychlor_red.htm
} 
(ER) $\alpha$ agonist and ER $\beta$ and androgen receptor (AR) antagonists (Cummings, 1997). The contamination by MXC can occur by inhalation or dermal contact, but the most effective contamination pathway seems to be through ingestion of contaminated food: MXC is absorbed along the gastrointestinal tract and is then metabolized by the liver following a detoxification pathway (Cummings, 1997). Even though MXC is metabolized by the liver, the estrogenic activity is carried out by its metabolites, which may even have a higher effectiveness than the original compound (Gaido et al., 2000).

Several studies have demonstrated the effects of MXC on reproductive organs in mice: neonatal treatments cause precocious vaginal opening in female mice as well as abnormal ovarian and reproductive tract morphology and premature senescence of the reproductive system in adult females (Eroschenko and Cooke, 1990; Eroschenko et al., 1995). In males, the same treatment inhibits organogenesis of accessory reproductive organs and decreases plasma testosterone levels (Cooke and Eroschenko, 1990; Eroschenko et al., 1995, 1997). Similar effects on reproductive organs have been also observed in male and female rats (for reviews see Chapin et al., 1997; Cummings, 1997; Laws et al., 2000).

MXC effects are also deleterious for the central nervous system, especially during development, leading to disrupted behavioral and sexual differentiation (Palanza et al., 1999, 2001b, 2002; Welshons et al., 1999; Gioiosa et al., 2007). Indeed, oral administration of MXC during the perinatal sensitive period causes organizational estrogen-like changes in behavior in female (increase of motor activity; Gray et al., 1988) and male rats (disruption of sexual behavior; Gray et al., 1989). In mice, embryonic exposure to MXC causes changes in reflex development, delayed onset of male intrasex aggression and increased rate of urine marking (Palanza et al., 1999).

While scientific interest in the effects of exposure to xenoestrogens has focused more on fertility and reproductive behavior effects, the effects on cognitive function have received less attention. This matter of fact seems to be surprising because, besides their importance for reproduction, estrogens play also a critical role in many higher cognitive abilities in vertebrates (McEwen, 2002; Rapp et al., 2003; Scharfman and Maclusky, 2005). For example, hippocampal memory dependent functions, such as spatial memory, are sensitive to estrogen in a variety of species including humans (Lephart et al., 2004).

The present study explored, for the first time, whether MXC administered during the perinatal period to male and female mice, at concentration that influenced other aspects of development (Palanza et al., 1999, 2001b, 2002; Gioiosa et al., 2007), would also affect learning and memory functions, especially those depending on the hippocampus. In addition, we wondered whether perinatal exposure to this EDC can also influence hippocampal neurogenesis, a form of plasticity based on persistent formation of adult-born neurons in the hippocampal dentate gyrus (DG). This is of particular importance as hippocampal neurogenesis participates in hippocampal-dependent memory (Koehl and Abrous, 2011).

\section{MATERIALS AND METHODS MATERNAL TREATMENT AND PROCEDURE}

Swiss CD1 mice were originally purchased from Janvier Breeding Center (Le Genest Saint-Isle, France) and were bred in our animal facility. Adult (2-3 months old) virgin females were timemated by being placed into the cage of a stud male for one night, beginning at 18:00 $\mathrm{h}$ (at the end of the light phase of the 12-h light/dark cycle). Mating was verified by the vaginal plug presence (gestational day 0 ). After mating pregnant females were housed three per cage $\left(45 \times 25 \times 15 \mathrm{~cm}^{3}\right)$ until the treatment started.

MXC was administered at a dose of $20 \mu \mathrm{g} / \mathrm{kg}$ (body weight)/day, which has been shown to affect behavioral development in previous experiments (Palanza et al., 2001b, 2002; Gioiosa et al., 2007). It is well below the $50 \mathrm{mg} / \mathrm{kg} /$ day lowest observed adverse effect level (LOAEL) and the $5 \mathrm{mg} / \mathrm{kg}$ predicted no observed adverse effect level (NOAEL; World Health Organization, 1996). This environmentally relevant dose is within the human exposure range and is considered as not teratogenic (see Brotons et al., 1995; Olea and Olea-Serrano, 1996; vom Saal and Hughes, 2005; Welshons et al., 2006). From gestational day 6 , pregnant dams were daily trained to drink a small volume $(0.1 \mathrm{ml})$ of sesame oil from a modified micropipette (i.e., with a larger hole). This training ensured that the treatment procedure was not stressful (Palanza et al., 2002). On gestational day 11 , females were individually housed and randomly assigned to one of the following treatment groups: sesame oil (control; $N=7$ ) or $\mathrm{MXC}$ at $20 \mu \mathrm{g} / \mathrm{kg} /$ day (Sigma Chemical; $N=7$ ) dissolved in sesame oil. Each female was fed $0.1 \mathrm{ml} / 50 \mathrm{~g}$ body weight/day of sesame oil with or without MXC $4 \mathrm{~h}$ after light onset and from gestational day 11 to postnatal day (PND) 8 . During this critical period for brain development in mice and rats, estrogens organize permanently and irreversibly specific brain circuitries (Arnold and Breedlove, 1985; Bigsby et al., 1999).

After dams gave birth, litters were sexed, culled to 10 pups ( $5 \pm$ 1 males and $5 \pm 1$ females) and returned to their mothers in the first $12 \mathrm{~h}$ of postnatal life. The offspring were weaned on PND 21 and group-housed with the same-sex littermates (5 mice/cage) during the whole experiment in $45 \times 25 \times 15 \mathrm{~cm}^{3}$ cages at $22 \pm$ $1{ }^{\circ} \mathrm{C}$, with a 12-h reversed dark/light cycle (lights off at 10:00 h). Water and pellet food (Safe, Augy, France) were available ad libitum. All animal studies were performed in accordance with the French and European legal requirements (Decree 2010/63/UE).

\section{EXPERIMENTAL SUBJECTS}

All behavioral tests were performed on one cohort of male and female control (OIL) and treated (MXC) mice $(N=12-15$ per treatment group) between 10:00 $\mathrm{h}$ and 18:00 h. The sequence of the tests was performed as follows: 1/elevated plus-maze (EPM), 2/openfield, 3/forced swim test (FST), 4/spontaneous alternation in a Y-maze and 5/the most aversive test, contextual fear conditioning. To allow a full recovery between tests, especially for those involving an aversive component, tests were spaced by a 1 week interval. A different cohort of animals was used for 5-Bromo-2Deoxyuridine (BrdU) injections ( $N=6$ per treatment group) so that the level of BrdU expression was not influenced by behavioral 
tests. To avoid any litter effect, no more than two pups originating from the same litter were included in the same experimental group for behavioral experiments; these two animals were tested in all experimental paradigms. For the BrdU experiment, no more than one pup originating from the same litter was included in the same experimental group. All tests were performed in a room adjacent to the room where animals were housed.

As the hormonal status may influence female responses (Marcondes et al., 2002; Simpson and Kelly, 2012), the phase of the estrous cycle was determined by vaginal smear cytology for each female before the behavioral tests. Cell type composition of the vaginal smears was determined (as described in McLean et al., 2012) and only females at the diestrus stage, thus showing low and stable levels of ovarian hormones (Butcher et al., 1974), were used.

\section{MEASUREMENT OF ANXIOLYTIC-LIKE BEHAVIOR IN THE ELEVATED PLUS-MAZE (EPM)}

The elevated plus-maze (EPM) consisted of a black plastic apparatus with four arms $(16 \times 5 \mathrm{~cm})$ set in a cross from a neutral central square $(5 \times 5 \mathrm{~cm})$. Two opposite arms were delimited by vertical walls (closed arms) whereas the two other opposite arms had unprotected edges (open arms). The maze was elevated $40 \mathrm{~cm}$ above the ground. At the beginning of the 5-min test session, each mouse was placed in the central neutral area, facing one of the open arms. The total time spent in the open arms was then scored. Time spent in the open arms was recorded when the mouse moved two forepaws and head into the arm. Results were expressed as the percentage of time spent in the open arms.

At 2 months of age, all subjects were tested for their behavior in the EPM as previously described (Keller et al., 2010; Martini et al., 2014). Control and MXC-treated mice were brought into the test room at least $1 \mathrm{~h}$ before the onset of behavioral testing and remained in the same room throughout the test. Mice were tested individually, during the dark phase of the dark-light cycle in a random order. The maze was cleaned with $70 \%$ ethanol to eliminate odors after each test.

\section{MEASUREMENT OF ANXIETY AND LOCOMOTOR ACTIVITY IN THE OPEN-FIELD TEST (OFT)}

Each animal was placed in an open field apparatus consisting of a rectangular area $\left(40 \times 40 \times 30 \mathrm{~cm}^{3}\right.$ (Martini and Valverde, 2012)). A total of 16 squares $(10 \times 10 \mathrm{~cm})$ were drawn with black lines on the white floor dividing the field into central and peripheral areas. To start the experiment, each mouse was placed in the central area of the field. The parameters measured during a 5 -min observation period were the time spent in the central area of the field, as indicator of anxiety-like behavior, and the total number of crossed squares, as indicator of locomotor activity.

\section{MEASUREMENT OF DEPRESSIVE-LIKE BEHAVIOR IN THE FORCED SWIM TEST (FST)}

Mice were placed into an opaque cylinder tank $(24 \mathrm{~cm}$ diameter, $53 \mathrm{~cm}$ height) filled to a depth of $30 \mathrm{~cm}$ with water maintained at $25^{\circ} \mathrm{C}$ to $27^{\circ} \mathrm{C}$. The water was changed after each animal, and the tank was thoroughly cleaned. Mice were placed for $6 \mathrm{~min}$ in the cylinder and scored for time spent actively swimming vs. floating (no leg or tail movement contributing to forward movement). The amount of time the mice spent floating during the last $4 \mathrm{~min}$ of the trial was recorded. An increase in floating is interpreted as an increase in depressive-like behavior (Porsolt et al., 2001).

\section{ASSESSMENT OF WORKING SPATIAL MEMORY THROUGH SPONTANEOUS ALTERNATION IN THE Y-MAZE}

Spontaneous alternation was assessed in a Plexiglas Y-maze apparatus, elevated $80 \mathrm{~cm}$ from the floor and located in the middle of a room containing a variety of extra-maze cues. The walls of the maze were $10 \mathrm{~cm}$ high; each arm was $50 \mathrm{~cm}$ long and $12.5 \mathrm{~cm}$ wide.

The test consisted of two visits in the apparatus separated by $90 \mathrm{~s}$ or $24 \mathrm{~h}$, to assess short- and long-term memory respectively (Sanderson et al., 2009). Briefly, during the first visit (sample phase), mice were placed at the end of a chosen arm (start arm) and allowed to explore two arms of the maze (the "start" arm and one of the two other arms called the "other" arm) for 5 min with the third arm closed ("novel" arm). Then, mice were removed from the maze and placed in a waiting cage (similar to the home cage) during a 90-s period to assess short-term memory or to their home cage during a 24 -h period to evaluate long-term memory. During the second visit (test phase), the mice were placed at the end of the start arm and allowed to explore freely all three arms of the maze for $2 \mathrm{~min}$ (the start, the other and the novel arm). Allocation of arms (other and novel) was counterbalanced within each experimental group. During the sample and the test phases, the time spent in each accessible arm was measured. The maze was cleaned with $70 \%$ ethanol between trials.

\section{CONTEXTUAL FEAR CONDITIONING TEST}

Fear conditioning was conducted in an operant chamber installed in a ventilated, sound insulated chest $(48 \times 36 \times 40 \mathrm{~cm})$. The chamber $(26 \times 18 \times 23 \mathrm{~cm})$ was a Plexiglas box equipped with a grid floor made of stainless steel rods $(2 \mathrm{~mm}$ in diameter), spaced at intervals of $6 \mathrm{~mm}$ center-to-center, through which scrambled electric shock could be delivered (Imetronic, Talence, France). Mice were held outside the experimental room in their home cages prior to testing and transported to the conditioning apparatus individually in standard mouse cages. Chamber was cleaned with $70 \%$ ethanol between each mouse.

The test consisted of two phases: (a) conditioning and (b) test of conditioned freezing to the same context. Conditioning was conducted on day 1 and consisted of two unsignaled deliveries of a 1-s, $0.6 \mathrm{~mA}$ footshocks. The first shock was delivered $3 \mathrm{~min}$ after the mice were placed into the chamber. Successive shock was delivered $3 \mathrm{~min}$ later and mice were removed $2 \mathrm{~min}$ after this second shock. On day 2, all mice were returned in the chamber. They were placed in the chamber for $8 \mathrm{~min}$, and freezing levels were recorded in the absence of any further stimulus.

\section{5-BROMO-2-DEOXYURIDINE (BrdU) INJECTIONS AND TISSUE PREPARATION}

To assess levels of cell survival in the hippocampal DG, adult mice received four i.p. injections of BrdU (50 mg/kg in $0.9 \%$ saline; Sigma-Aldrich, Saint-Quentin Fallavier, France), with $2 \mathrm{~h}$ intervals (between 11:00 and 17:00 h) and were killed 21 days 
later. At the end of the experiment, animals were anesthetized and transcardially perfused with $1 \%$ sodium nitrite in phosphate buffer saline, followed immediately by $4 \%$ cold paraformaldehyde solution in $0.1 \mathrm{M}$ phosphate buffer ( $\mathrm{pH}$ 7.4). Brains were removed and post-fixed in $4 \%$ paraformaldehyde for $2 \mathrm{~h}$ and they were then placed overnight in a $30 \%$ sucrose solution in PBS, frozen in liquid isopentane at $-35^{\circ} \mathrm{C}$ and stored in a deep freezer at $-80^{\circ} \mathrm{C}$ until sectioning.

Brains were serially cut in the coronal planes at $30 \mu \mathrm{m}$ thickness with a cryostat. The plane of sectioning was oriented to match the drawings corresponding to the coronal sections of the mouse brain atlas (Franklin and Paxinos, 1997). Serial sections were collected in a cryoprotectant solution at $-20^{\circ} \mathrm{C}$ (Watson et al., 1986). Every fourth section (a section every $120 \mu \mathrm{m}$ ) was processed for BrdU immunohistochemistry and for BrdU/NeuN double immunofluorescence labeling.

\section{BrdU IMMUNOHISTOCHEMISTRY}

To reveal BrdU positive cells, a peroxidase single-immunolabeling was used. Sections were treated with TBS $0.025 \mathrm{M}, \mathrm{pH} 7.4-$ Triton $0.3 \%$-Azide $0.1 \%$-BSA $1 \%$ (TBSTA-BSA) for $1 \mathrm{~h}$ to increase permeability of plasma membrane. After one rinse in TBS, sections were treated with $2 \mathrm{~N} \mathrm{HCl}$ in TBS for $25 \mathrm{~min}$ at $37^{\circ} \mathrm{C}$ in order to denaturate the DNA. After three rinses in TBS, sections were incubated overnight in primary rat antiBrdU (1:300; AbCys AbC117-7513, Paris, France) in TBSTABSA. The next day, sections were rinsed three times in TBS, and were incubated for $1: 30 \mathrm{~h}$ with a goat anti-rat peroxidase (1:300; Jackson 112-036-003, USA) in TBS $0.025 \mathrm{M}, \mathrm{pH} 7.4-$ Saponine $0.3 \%$-BSA $1 \%$ (TBS-Saponine-BSA). Finally, after two rinses in TBS and two rinses in Tris- $\mathrm{HCl} 0.05 \mathrm{M}, \mathrm{pH} 7.6$, sections were reacted for peroxidase detection in a solution of $3,3^{\prime}$-Diaminobenzidine tetrahydrochloride $(0.15 \mathrm{mg} / \mathrm{ml}$; Sigma $)$ containing $0.001 \% \mathrm{H}_{2} \mathrm{O}_{2}$ and $0.46 \%$ nickel ammonium sulphate (DAB-Ni- $\mathrm{H}_{2} \mathrm{O}_{2}$ revelation).

\section{DOUBLE IMMUNOFLUORESCENCE LABELING BrdU/NeuN}

To characterize the phenotype of BrdU positive cells in the DG, we used NeuN, a marker for postmitotic neurons. A double immunofluorescence labeling was performed against BrdU and NeuN. Coronal sections of the hippocampus were treated with TBS $0.025 \mathrm{M}$, pH 7.4-Triton 0.3\%-Azide 0.1\%-BSA 0.1\% (TBSTA-BSA) for $1 \mathrm{~h}$ to increase permeability of plasma membrane. After one rinse in TBS, sections were treated with $2 \mathrm{~N} \mathrm{HCl}$ in TBS for $25 \mathrm{~min}$ at $37^{\circ} \mathrm{C}$ in order to denaturate the DNA. After three rinses in TBS, sections were incubated overnight in primary antibodies (BrdU, 1:300, AbCys AbC117-7513, Paris, France; NeuN, 1:1000, Chemicon MAB377, clone A60, Millipore, St. Quentin-en-Yvelines, France) in TBSTA-BSA. The next day, sections were rinsed three times in TBS, and were incubated for 1:30 h with CY3Donkey anti-rat (1:300, Jackson ImmunoResearch 712-165-153, United Kingdom), and 488 donkey antimouse (1:300, AlexaFluor A11029, Molecular Probes, Eugene, Oregon, USA) in TBS $0.025 \mathrm{M}, \mathrm{pH}$ 7.4-Saponine 0.3\%-BSA $1 \%$ (TBS-Saponine-BSA). After four rinses in TBS, sections were immersed in a Hoechst solution for $2 \mathrm{~min}$ (Hoechst 33258, $2 \mu \mathrm{g} / \mathrm{ml}$ in water, Invitrogen, USA), rinsed twice in water, dried and then cover-slipped under fluoromount-G (SouthernBiotech, Birmingham, AL, USA) and stored at $+4^{\circ} \mathrm{C}$ in the dark.

\section{QUANTIFICATION}

The number of BrdU positive cells was assessed by counting peroxidase/DAB-stained coronal sections of the DG with a light microscope on a magnification of $20 \mathrm{x}$ and cell count analysis software (computerized image analysis: Mercator, Explora Nova, La Rochelle, France). The counter was blind to the experimental group. Six coronal sections were selected through the dorsal hippocampus. Areas of the granule cell layer (GCL) and the subgranular zone (SGZ) of the DG were delimited and measured with an 10x objective. The density of BrdU positive cells was then calculated by dividing the numbers of BrdU positive cells by the layer area.

To determine the proportion of new cells, which expressed BrdU and NeuN, a confocal laser-scanning microscope (LSM 700, Zeiss, Germany) was used. The corresponding six coronal sections of the BrdU positive cells counting were selected through the dorsal hippocampus. Each BrdU positive cell was analyzed in its entire $z$-axis, with $0.5 \mu \mathrm{m}$ step intervals, using an $40 \mathrm{x}$ oilimmersion objective to identify double immunolabeling.

\section{STATISTICAL ANALYSIS}

All the analyses were performed using the software Statistica 6.0 (StatSoft Inc., Tulsa, OK, USA). Differences were considered significant when $p<0.05$. Data are represented as mean \pm SEM. Effects of MXC in male and female mice were compared using two-way analyses of variance (ANOVA), with sex and perinatal exposure as independent factors. Significant effects revealed by ANOVA were further explored using the post-hoc Fisher's LSD test. The potential litter effect was statistically evaluated using a one-way ANOVA, with litter as independent factor. However, as no significant litter effect was detected, we did not present these results in the following section.

\section{RESULTS}

\section{ELEVATED PLUS-MAZE (EPM)}

A two-way ANOVA (with sex and perinatal exposure as independent factors) on the percentage of time spent in the open arm revealed a significant effect of the treatment $\left(F_{(1,46)}=17.690\right.$, $p<0.001)$, but no effect of $\operatorname{sex}\left(F_{(1,46)}=0.107, p=0.745\right)$ or interaction between sex and treatment $\left(F_{(1,46)}=0.126, p=0.724\right)$. In fact, both male and female mice perinatally exposed to MXC exhibited a significant increase in anxiety-like behavior evaluated in the EPM compared to control animals, since the percentage of time spent in the open arms was lower compared to control groups (Figure 1 ).

\section{OPEN FIELD TEST (OFT)}

Different responses were evaluated in the open-field test (OFT): the time spent in the central area of the field, as indicator of anxiety-like behavior, and the total number of crossed squares, as indicator of locomotor activity. The time spent in the central area was significantly lower in females by comparison with males (sex: 


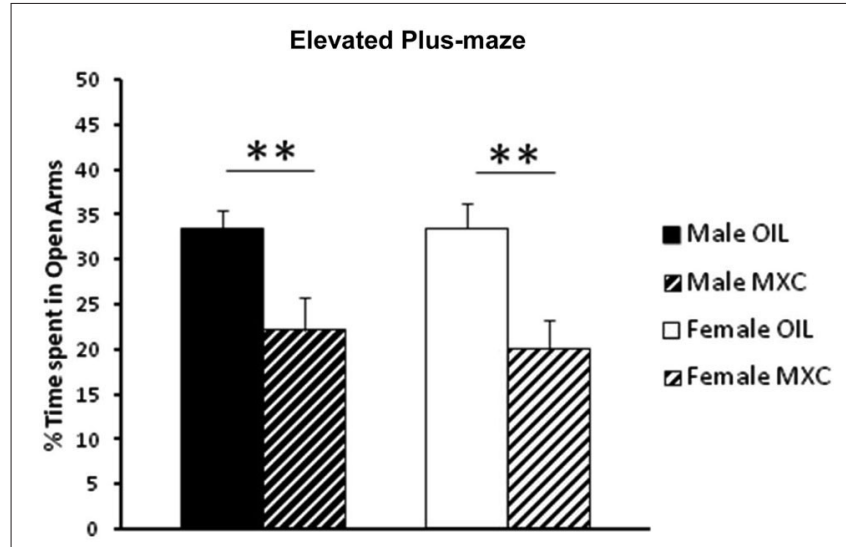

FIGURE 1 | Percent of open-arm time in the EPM. Perinatal exposure to MXC in both male and female mice revealed a significant decrease in the percentage of time spent in the open arms compared to control groups. Data are expressed as mean \pm SEM ${ }^{* *} p<0.01$.

$\left.F_{(1,56)}=4.604, p=0.036\right)$, and significantly decreased in MXCtreated mice compared to controls (treatment: $F_{(1,56)}=31.774$, $p<0.001$; sex ${ }^{\star}$ treatment: $\left.F_{(1,56)}=0.402, p=0.529\right)($ Figure 2A).

Two-way ANOVA revealed no effects of sex or treatment on locomotor activity (total number of crossed squares) (sex: $F_{(1,56)}=0.735, p=0.395$; treatment: $F_{(1,56)}=0.151, p=0.699$; sex treatment: $\left.F_{(1,56)}=1.604, p=0.211\right)$ (Figure 2B).

\section{FORCED SWIM TEST (FST)}

Male and female mice exposed to MXC during the perinatal period exhibited no difference in the depressive-like profile evaluated in the FST. Two-way ANOVA indicated no effect of sex $\left(F_{(1,44)}=2.441, p=0.125\right)$, treatment $\left(F_{(1,44)}=0.018, p=0.894\right)$, and no interaction between these two factors $\left(F_{(1,44)}=0.064\right.$, $p=0.801$; Figure 3 ) on the time the animal spent floating during the recorded period.

\section{SPONTANEOUS ALTERNATION IN THE Y-MAZE}

Regarding short-term memory assessment, two-way analysis of the percentage of time spent in the novel arm [(time spent in the novel arm divided by three arms $) \times 100$ ], revealed an effect of the treatment $\left(F_{(1,56)}=20.282, p<0.001\right)$ and an almost significant interaction sex treatment $\left(F_{(1,56)}=3.706, p=0.059\right)$, but no effects of $\operatorname{sex}\left(F_{(1,56)}=1.013, p=0.318\right)$ during the test phase (Figure 4).

This effect was specific of short-term memory, because when long-term memory was assessed after $24 \mathrm{~h}$, two-way ANOVA of the percentage of time spent in the novel arm, revealed no significant effect of the treatment, of sex and no interaction sex ${ }^{\star}$ treatment $\left(F_{(1,56)}=3.242, p=0.077 ; F_{(1,56)}=1.981, p=\right.$ $0.165 ; F_{(1,56)}=1.313, p=0.257$ respectively) during the test phase (Figure 4).

\section{CONTEXTUAL FEAR CONDITIONING TEST}

Two-way ANOVA calculated for the percentage of time the animal spent freezing during the recorded period revealed a significant
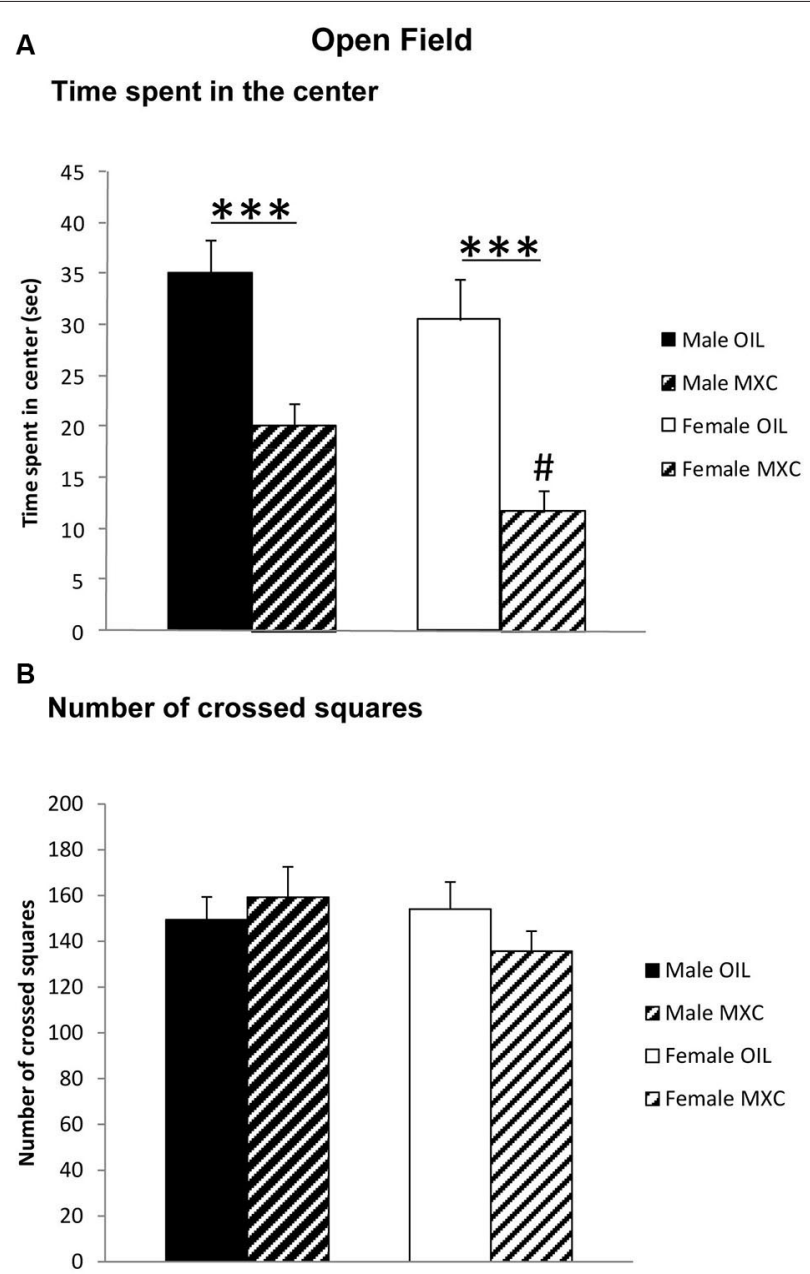

FIGURE 2 | (A) Time spent in the central area and (B) total number of crossed squares in an open field. Perinatal MXC exposure induced a decrease in the time spent in the central area in female compared to male mice and a significantly decrease in MXC treated mice compared to control mice. No differences of the total number of crossed squares were detected, as indicator of locomotor activity. Data are expressed as mean \pm SEM. ${ }^{* *} p<0.001 ; \# p<0.05$ males vs. females.

effect of $\operatorname{sex}\left(F_{(1,56)}=80.880, p<0.001\right)$ with the females spending a greater percentage of time freezing than males. The percentage of contextual freezing was also significantly higher in MXC treated mice compared to control mice (significant effect of the treatment: $F_{(1,56)}=18.289, p<0.001$; sex treatment: $\left.F_{(1,56)}=1.576, p=0.215\right)$. Subsequent post-hoc Fisher's LSD analysis revealed an increase in the time spent freezing in MXC treated mice $(p=0.04$ and $p<0.001$ in male and female mice respectively) (Figure 5).

\section{HIPPOCAMPAL NEUROGENESIS}

The perinatal MXC treatment led to a significant increase in cells survival in the DG of the hippocampus in both sexes compared to corresponding controls. In addition, density of cells survival was higher in males compared to females. Indeed, two-way ANOVA (sex and treatment as independent factors) revealed a 


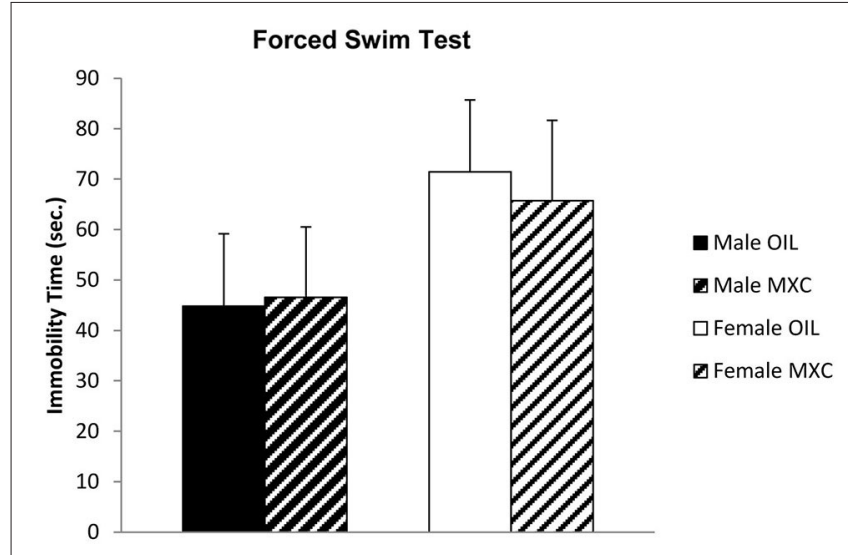

FIGURE 3 | Time spent floating, in seconds, in the FST. Male and female mice perinatally exposed to MXC exhibited no effects in the depressive-like profile evaluated in the FST. Data are expressed as mean \pm SEM.

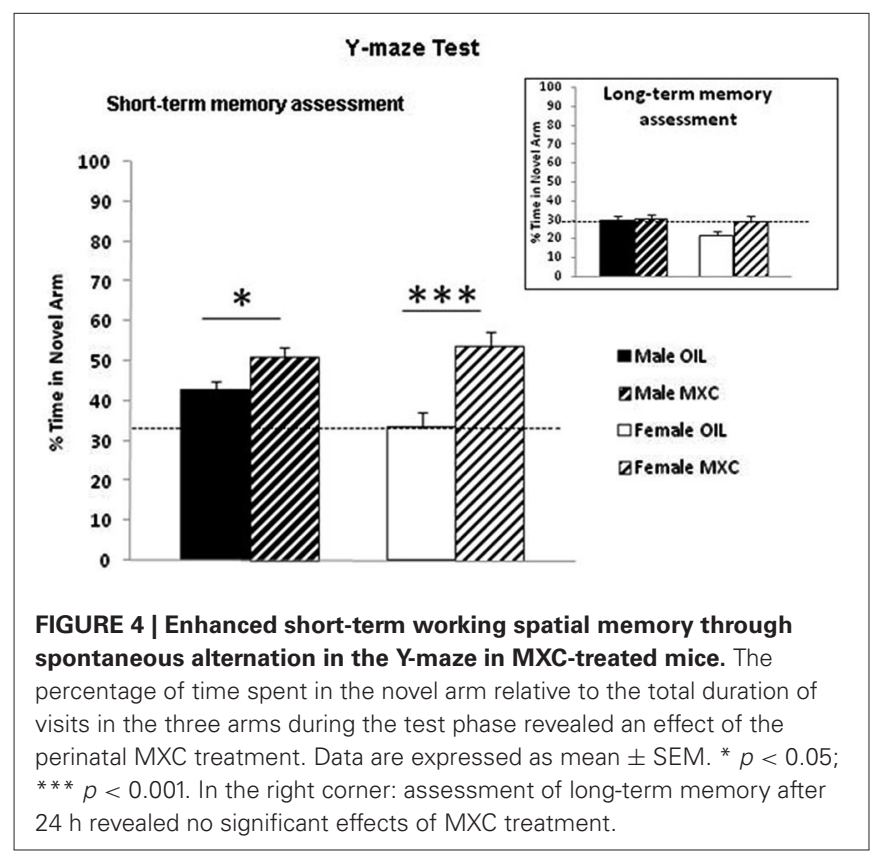

significant effect of sex and treatment $\left(F_{(1,20)}=6.742, p=0.017\right.$ and $F_{(1,20)}=17.698, p<0.001$ respectively) but no interaction between both factors $\left(F_{(1,20)}=0.129, p=0.723\right.$; Figures 6A-B).

The percentage of BrdU-positive cells expressing NeuN in the DG of hippocampus $(83 \% \pm 2.1)$ did not significantly differ between groups. Two-way ANOVA revealed no effects of sex $\left(F_{(1,20)}=0.300, p=0.590\right)$, treatment $\left(F_{(1,20)}=0.028, p=0.870\right)$ and no interaction between these two factors $\left(F_{(1,20)}=0.064\right.$, $p=0.803$; Figures $7 \mathrm{~A}-\mathbf{B}$ ).

\section{DISCUSSION}

While the effects of exposure to xenoestrogens have been largely documented on fertility and reproductive behaviors, the effects on cognitive function have received less attention. Thus,

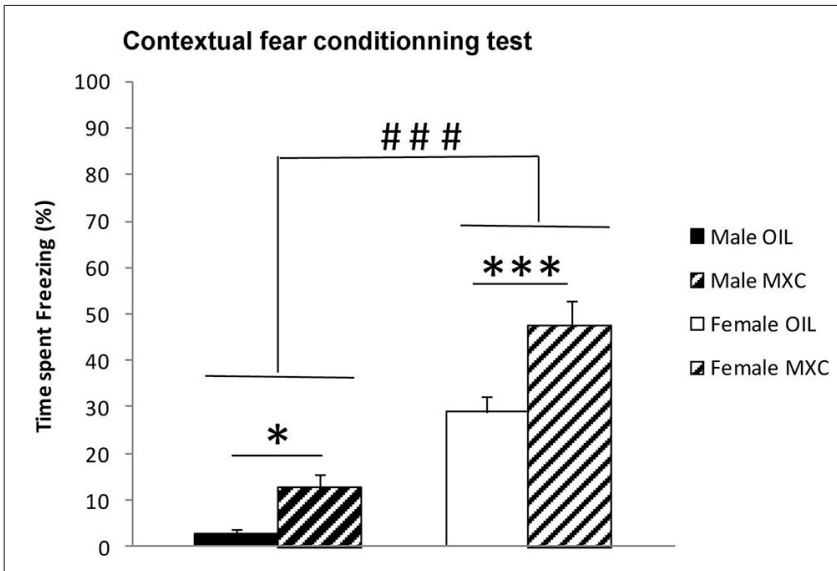

FIGURE 5 | Freezing behavior expressed as percentage of time spent freezing during the recorded period in contextual fear conditioning test. The percentage of time that the animal spent freezing revealed a significant effect of sex, with the females spending a greater percentage of time freezing than males. Percentage of contextual freezing was also significantly higher in MXC-treated mice compared to control. Data are expressed as mean \pm SEM. ${ }^{*} p<0.05 ;{ }^{* * *} p<0.001$; \#\#\# $p<0.001$ in Females vs. Males.

an important aspect of this study is that our data extend the adverse effects of MXC to non-reproductive behaviors at an environmentally relevant dose within the human exposure range. The overall result of our study is that maternal exposure to a very low dose of MXC during fetal and neonatal periods had an enduring effect on hippocampus-dependent memory and plasticity as well as on emotional behaviors in adulthood.

We first assessed explorative and emotional behavior in EPM and OFT. We found no difference in control male and female groups in both experimental paradigms, but both sexes perinatally exposed to MXC showed an increase in anxiety-like behaviors: MXC exposed mice spent less time than controls in the open arms of the EPM, and central area of the OFT. Since the number of crossed squares in the OFT did not vary between control and MXC exposed mice, the differences encountered are not related to a possible locomotor impairment induced by MXC.

We have explored whether this increased anxiety effect of MXC could also lead to depressive-like behavior. No effect of MXC treatment was detectable on the time the mice spent floating in the FST. Thus we concluded that perinatal MXC exposure specifically increased anxiety without inducing any depressivelike phenotype.

Our results in the EPM are in agreement with data obtained in the OFT, but also with previous behavioral tests in female mice (Palanza et al., 2002; Gioiosa et al., 2007) showing that MXC exposure lead to an anxiogenic effect, with a decrease in the time spent in the open arms of the EPM and a lower exploration of the OFT. By contrast, the effects observed in male mice in our experiment are not in accordance with those reported in previous studies. Indeed, sex differences were observed in control mice in both EPM and OFT, with unexposed males 


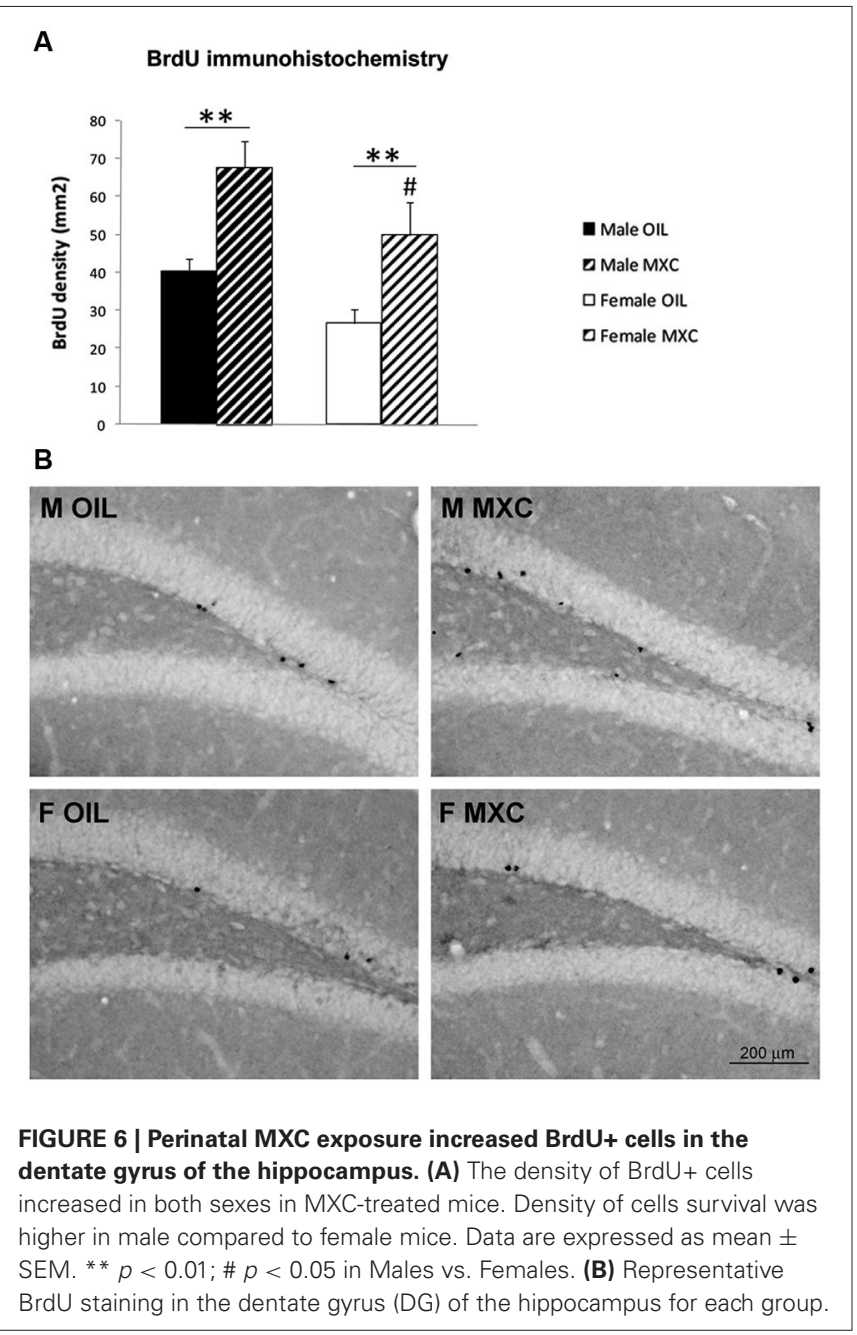

being more anxious and less prone to explore a novel environment when compared with control females (Gioiosa et al., 2007). In addition, perinatal exposure to MXC, at the same dose than that used in our study, did not induce any effect in males (Gioiosa et al., 2007). Although the reasons for this discrepancy are not completely clear, it must be noticed that sex differences in anxiety-like behavior, for example when measured in the OFT, may be not always observed in CD-1 mice, the strain used in the present study (Palanza et al., 2001a). In addition, in other experiments, using perinatal exposure to daidzein, a phytoestrogen compound with higher estrogenic activity than other isoflavones, adult male mice showed significantly less exploration and higher levels of anxiety (Yu et al., 2013), thus confirming that perinatal exposure to estrogenic compounds can have long-term anxiogenic consequences in adulthood.

Then, we explored whether perinatal exposure to MXC could impact hippocampal dependent memory assessed through two complementary tests, namely the Y-maze spontaneous alternation test which evaluates spatial short-term memory and contextual fear conditioning which is dependent upon spatial and contextual cues and is a form of long-term hippocampus

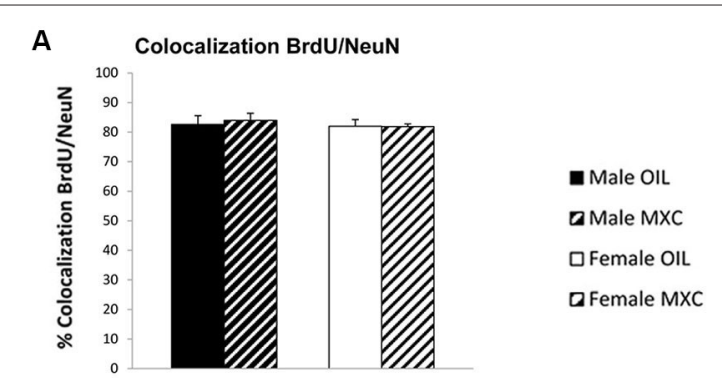

\section{B Double immunofluorescence labeling BrdU/NeuN}

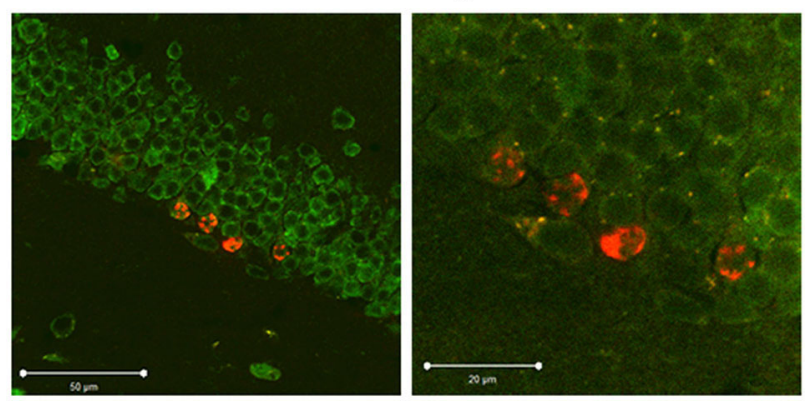

FIGURE 7 | Number and phenotyping of BrdU+ cells in the dentate gyrus of the hippocampus. (A) The percentage of BrdU+cells that expressd NeuN did not significantly differ according groups. Data are expressed as mean \pm SEM. (B) Representative confocal BrdU(red)/NeuN(green) double-labeled images in the DG of the hippocampus at low (left panel) and high (right panel) magnification.

dependent memory. Indeed, it has been shown that a lesion of the hippocampus disrupts spatial memory performances in both the Y-maze spontaneous alternation test (Sanderson et al., 2009) and contextual fear conditioning (Anagnostaras et al., 2001).

For both tests, the obtained results showed a very significant effect of the treatment in both sexes: MXC-treated groups spent a greater proportion of time in the novel arm of the Y-maze and they also expressed a higher percentage of freezing time when re-exposed to the conditioning context. Although these results may appear surprising, a small body of literature has shown that EDCs may facilitate cognitive function in some cases. For example, exposure of male rats to $17 \alpha$-ethinylestradiol during development results in enhanced spatial working memory during the acquisition phase of a Morris water maze test in male rats (Corrieri et al., 2007), a test that is also highly dependent upon hippocampus. In addition, adult male mice exposed to daidzein during the perinatal period, showed also a tendency to improve spatial learning and memory in adulthood (Yu et al., 2013). These results thus further suggest an organizational effect of estrogenic EDCs or phytoestrogens on hippocampus dependent memory.

In the Y-maze test, male mice exhibited higher performances compared to female mice. This finding is in accordance with previous studies showing that males generally outperform females on tasks that are considered to be hippocampus-dependent (for reviews see Galea et al., 2006; Luine, 2008). During the test phase of the conditioning to context task, opposite effect of sex on 
memory were observed. Indeed, control male mice exhibited less conditioned freezing to context than female. Both, the Y-maze and the contextual fear conditioning tasks are considered to be hippocampus dependent tasks. Nevertheless, both tasks assess different forms of hippocampus dependent memory and strongly differ in terms of emotional load. First, the Y-maze task is considered to assess short-term hippocampus dependent memory performances whereas the context test (in the fear conditioning to context task) assess long-term hippocampus dependent memory performances. Second, contextual fear conditioning is considered to assess hippocampus dependent memory when animals are exposed to emotionally laden stimuli which is not the case for the Y-maze task. In line with this, previous studies showed that temporary inactivation or permanent lesions of the amygdala, a brain region fully involved in emotional learning, severely interferes with contextual fear conditioning (Calandreau et al., 2005; Onishi and Xavier, 2010). On the contrary, in the Y-maze test (Sanderson et al., 2009), amygdala lesioned mice were still able to discriminate between a familiar and a novel arm. Consequently our findings suggest that male and female CD1 mice may have distinct memory performances depending on the type of memory targeted. These effects, although interesting, will deserve supplementary investigations to be fully understood.

The present enhancing effect of MXC on hippocampus dependent memory may be related to its well-established estrogenic action (Cummings, 1997). In line with this view, low doses of $17 \beta$-estradiol were previously reported to facilitate contextual fear conditioning in female rats (Barha et al., 2010). Moreover, aromatase-knockout (ArKO) male and female mice, which are unable to produce estrogens, exhibited deficits in spatial working memory assessed in the spontaneous alternation Y-maze test (Martin et al., 2003). These findings thus suggest that estrogenic EDCs could act during development to alter the organization of hippocampal dependent memory, even if we have not used a positive control (e.g., estradiol or the synthetic estrogen diethylstilbestrol). However, we cannot ascribe the observed behavioral effects only to an estrogenic action of MXC. In fact, it must be recognized that in addition to its documented estrogenicity, MXC may exert other effects on the developing brain; in fact, it has been shown to interact with multiple receptors (Ghosh et al., 1999), and to exert antiandrogenic action, as well (Gray et al., 1999).

Finally, Palanza et al. (2002) have shown a slight, but significant, perturbation of maternal behavior of females that had consumed very low doses of MXC during the last week of gestation. Even if the exposition time of MXC differs from our study (MXC was administered only during the gestational period, from day 11 to 17), we cannot exclude that variations in maternal care can have consequences for the subsequent behavioral development of the offspring and that some of the differences observed between MXC and control group may arise from such difference in maternal behavior.

Perinatal MXC treatment also led to a significant increase in cell survival in the DG of the hippocampus in both sexes compared to controls. Interestingly, the effect of MXC on hippocampal neurogenesis cannot be the consequence of confounding effects due to behavioral tests because independent groups of animals have been used to perform behavioral tests and to assess DG neurogenesis. Moreover, MXC treatment did not influence cell differentiation, because the proportion of surviving neurons, assessed through BrdU/NeuN double immunofluorescence labeling was stable in treated and untreated groups, suggesting that MXC affected only proliferation and/or survival processes. The present effect of MXC on hippocampal neurogenesis is very congruent with the enhancing effect of MXC on hippocampus dependent memory. Indeed, hippocampal adult neurogenesis has been shown to be a new form of plasticity that underlies hippocampus dependent learning and memory (Koehl and Abrous, 2011; Lafenetre et al., 2011). In particular, previous studies reported a positive correlation between reduced adult neurogenesis and deficits in contextual conditioning or spatial memory (Saxe et al., 2006; Winocur et al., 2006; Dupret et al., 2008; Imayoshi et al., 2008; WarnerSchmidt et al., 2008; Deng et al., 2009; Hernández-Rabaza et al., 2009; Snyder et al., 2009). Regarding our experimental conditions, it has been well demonstrated that contextual fear conditioning is dependent upon DG neurogenesis (Drew et al., 2010).

By contrast, data assessing the effect of estrogens treatment during the perinatal period on adult hippocampal neurogenesis are quite sparse. However, it is noticeable that $17 \beta$-estradiol treatment increases hippocampal cell proliferation in neonatal females and that this effect persisted until at least 3 weeks of age (Bowers et al., 2010). In addition, administering the aromatase inhibitor, formestane, or the estrogen receptor antagonist tamoxifen, during the perinatal period, significantly decreased the number of new cells in the DG observed 3 weeks later in males (Bowers et al., 2010). As a whole, these results suggest that the estrogenic properties of perinatal MXC may be responsible for both increased hippocampal memory and a higher rate of cell survival observed in the DG in adulthood.

It is interesting to notice that adult treatment with $17 \beta$ estradiol has been shown to increase both contextual fear conditioning (Barha et al., 2010) and adult DG neurogenesis in female rodents (see for example Ormerod et al., 2004; McClure et al., 2013), even if some variations in the effects may be observed according to doses, exposure durations or animal models. In addition, 17 $\beta$-estradiol also led to a significant increase in the percentage of new neurons expressing the immediate early gene product zif268 in response to spatial memory retrieval (McClure et al., 2013), leading to the conclusion that these new neurons are activated during a spatial task, which may be functionally relevant (Veyrac et al., 2013).

Finally, it is striking to notice that the animals exposed to MXC and exhibiting therefore a higher state of anxiety, express also both a higher level of hippocampal neurogenesis and enhanced memory performances in the Y-maze and contextual fear conditioning tests. Although discussed, it is generally assumed that stressful situations and anxiety inhibit adult hippocampal neurogenesis and disrupt cognitive function. It has even been proposed that reduced neurogenesis was involved in the pathogenesis of anxiety related behavior (Snyder et al., 2011). Nevertheless, several experiments demonstrated that the link between anxiety or affective disorders 
and hippocampal neurogenesis is not trivial. Some experiments, using cranial irradiation or antimitotics agents report no effect of hippocampal neurogenesis ablation on anxiety related behaviors (Petrik et al., 2012 for review). Disruption of neurogenesis via inducible transgenic mouse models was even reported to increase or decrease anxiety behaviors (Revest et al., 2009; Onksen et al., 2011). Moreover, researches also provided evidence that some amount of stress or level of anxiety can be useful for learning and memory (Joels et al., 2006). Therefore, MXC treatment would have positive effects on hippocampal neurogenesis and hippocampus dependent memory through an increase in anxiety/stress level. Nevertheless, future studies will be required to fully understand the relationships between the present observed effects of MXC on anxiety, hippocampal neurogenesis and memory.

In conclusion, perinatal exposure to MXC induced durable effects on cognitive functions in adulthood such as increased anxiety and higher performances in hippocampal dependent memory tests, these later effects being correlated with a higher rate of cell survival in the DG of the hippocampus. Although these results correlate well with the known estrogenic properties of MXC, the exact mechanisms involved need to be determined. Moreover further investigations will be required to fully assess effect of MXC on different memory systems and other cognitive functions.

\section{ACKNOWLEDGMENTS}

This work has been funded through programs of the French national research agency (ANR Bimuce CESA 2009-2013) and ANSES (Programme Santé-Environnement-Travail). We thank the help of Claude Cahier, Marine Cirot and Deborah Crespin for the care of the animals and their help during the experiments.

\section{REFERENCES}

Anagnostaras, S. G., Gale, G. D., and Fanselow, M. S. (2001). Hippocampus and contextual fear conditioning: recent controversies and advances. Hippocampus 11, 8-17. doi: 10.1002/1098-1063(2001)11:1<8::aid-hipo1015>3.0.co;2-7

Arnold, A. P., and Breedlove, S. M. (1985). Organizational and activational effects of sex steroids on brain and behavior: a reanalysis. Horm. Behav. 19, 469-498. doi: 10.1016/0018-506x(85)90042-x

Barha, C. K., Dalton, G. L., and Galea, L. A. (2010). Low doses of 17alpha-estradiol and 17beta-estradiol facilitate, whereas higher doses of estrone and 17alphaand 17beta-estradiol impair, contextual fear conditioning in adult female rats. Neuropsychopharmacology 35, 547-559. doi: 10.1038/npp.2009.161

Bempah, C. K., and Donkor, A. K. (2011). Pesticide residues in fruits at the market level in Accra Metropolis, Ghana, a preliminary study. Environ. Monit. Assess. 175, 551-561. doi: 10.1007/s10661-010-1550-0

Bigsby, R., Chapin, R. E., Daston, G. P., Davis, B. J., Gorski, J., Gray, L. E., et al. (1999). Evaluating the effects of endocrine disruptors on endocrine function during development. Environ. Health Perspect. 107(Suppl. 4), 613-618. doi: 10. 1289/ehp.99107s4613

Bowers, J. M., Waddell, J., and McCarthy, M. M. (2010). A developmental sex difference in hippocampal neurogenesis is mediated by endogenous oestradiol. Biol. Sex Differ. 1:8. doi: 10.1186/2042-6410-1-8

Brotons, J. A., Olea-Serrano, M. F., Villalobos, M., Pedraza, V., and Olea, N. (1995). Xenoestrogens released from lacquer coatings in food cans. Environ. Health Perspect. 103, 608-612. doi: 10.1289/ehp.95103608

Butcher, R. L., Collins, W. E., and Fugo, N. W. (1974). Plasma concentration of LH, FSH, prolactin, progesterone and estradiol-17beta throughout the 4-day estrous cycle of the rat. Endocrinology 94, 1704-1708. doi: 10.1210/endo-94-6-1704

Calandreau, L., Desmedt, A., Decorte, L., and Jaffard, R. (2005). A different recruitment of the lateral and basolateral amygdala promotes contextual or elemental conditioned association in Pavlovian fear conditioning. Learn. Mem. 12, 383-388. doi: 10.1101/lm.92305

Chapin, R. E., Harris, M. W., Davis, B. J., Ward, S. M., Wilson, R. E., Mauney, M. A., et al. (1997). The effects of perinatal/juvenile methoxychlor exposure on adult rat nervous, immune and reproductive system function. Fundam. Appl. Toxicol. 40, 138-157. doi: 10.1006/faat.1997.2381

Cooke, P. S., and Eroschenko, V. P. (1990). Inhibitory effects of technical grade methoxychlor on development of neonatal male mouse reproductive organs. Biol. Reprod. 42, 585-596. doi: 10.1095/biolreprod42.3.585

Corrieri, L., Della Seta, D., Canoine, V., and andFusani, L. (2007). Developmental exposure to xenoestrogen enhances spatial learning in male rats. Horm. Behav. 51, 620-625. doi: 10.1016/j.yhbeh.2007.03.002

Cummings, A. M. (1997). Methoxychlor as a model for environmental estrogens. Crit. Rev. Toxicol. 27, 367-379. doi: 10.3109/10408449709089899

Deng, W., Saxe, M. D., Gallina, I. S., and Gage, F. H. (2009). Adult-born hippocampal dentate granule cells undergoing maturation modulate learning and memory in the brain. J. Neurosci. 29, 13532-13542. doi: 10.1523/JNEUROSCI. 3362-09.2009

Drew, M. R., Denny, C. A., and Hen, R. (2010). Arrest of adult hippocampal neurogenesis in mice impairs single- but not multiple-trial contextual fear conditioning. Behav. Neurosci. 124, 446-454. doi: 10.1037/a0020081

Dupret, D., Revest, J. M., Koehl, M., Ichas, F., De Giorgi, F., Costet, P., et al. (2008). Spatial relational memory requires hippocampal adult neurogenesis. PLoS One 3:e1959. doi: 10.1371/journal.pone.0001959

Eroschenko, V. P., Abuel-Atta, A. A., and Grober, M. S. (1995). Neonatal exposures to technical methoxychlor alters ovaries in adult mice. Reprod. Toxicol. 9, 379387. doi: 10.1016/0890-6238(95)00025-6

Eroschenko, V. P., and Cooke, P. S. (1990). Morphological and biochemical alterations in reproductive tracts of neonatal female mice treated with the pesticide methoxychlor. Biol. Reprod. 42, 573-583. doi: 10.1095/biolreprod42.3.573

Eroschenko, V. P., Swartz, W. J., and Ford, L. C. (1997). Decreased superovulation in adult mice following neonatal exposures to technical methoxychlor. Reprod. Toxicol. 11, 807-814. doi: 10.1016/s0890-6238(97)00064-6

Fisher, J. S. (2004). Are all EDC effects mediated via steroid hormone receptors? Toxicology 205, 33-41. doi: 10.1016/j.tox.2004.06.035

Franklin, K. B. J., and Paxinos, G. (1997). The Mouse Brain in Stereotaxic Coordinates. New York, NY: Academic Press.

Frye, C. A., Bo, E., Calamandrei, G., Calza, L., Dessi-Fulgheri, F., Fernandez, M., et al. (2012). Endocrine disrupters: a review of some sources, effects and mechanisms of actions on behaviour and neuroendocrine systems. J. Neuroendocrinol. 24, 144-159. doi: 10.1111/j.1365-2826.2011.02229.x

Gaido, K. W., Maness, S. C., McDonnell, D. P., Dehal, S. S., Kupfer, D., and Safe, S. (2000). Interaction of methoxychlor and related compounds with estrogen receptor alpha and beta and androgen receptor: structure-activity studies. Mol. Pharmacol. 58, 852-858. doi: 10.1124/mol.58.4.852

Galea, L. A., Spritzer, M. D., and Pawluski, J. L. (2006). Gonadal hormone modulation of hippocampal neurogenesis in the adult. Hippocampus 16, 225 232. doi: 10.1002/hipo.20154

Ghosh, D., Taylor, J. A., Green, J. A., and Lubahn, D. B. (1999). Methoxychlor stimulates estrogen-responsive messenger ribonucleic acids in mouse uterus through a non-estrogen receptor (non-ER) alpha and non-ER beta mechanism. Endocrinology 140, 3526-3533. doi: 10.1210/en.140.8.3526

Gioiosa, L., Fissore, E., Ghirardelli, G., Parmigiani, S., and Palanza, P. (2007). Developmental exposure to low-dose estrogenic endocrine disruptors alters sex differences in exploration and emotional responses in mice. Horm. Behav. 52, 307-316. doi: 10.1016/j.yhbeh.2007.05.006

Gray, L. E. Jr., Ostby, J. S., Ferrell, J. M., Sigmon, E. R., and Goldman, J. M. (1988). Methoxychlor induces estrogen-like alterations of behavior and the reproductive tract in the female rat and hamster: effects on sex behavior, running wheel activity and uterine morphology. Toxicol. Appl. Pharmacol. 96, 525-540. doi: 10. 1016/0041-008x(88)90012-9

Gray, L. E. Jr., Ostby, J., Cooper, R. L., and Kelce, W. R. (1999). The estrogenic and antiandrogenic pesticide methoxychlor alters the reproductive tract and behavior without affecting pituitary size or $\mathrm{LH}$ and prolactin secretion in male rats. Toxicol. Ind. Health 15, 37-47. doi: 10.1177/074823379901500105

Gray, L. E. Jr., Ostby, J., Ferrell, J., Rehnberg, G., Linder, R., Cooper, R., et al. (1989). A dose-response analysis of methoxychlor-induced alterations of reproductive development and function in the rat. Fundam. Appl. Toxicol. 12, 92-108. doi: 10. 1016/0272-0590(89)90065-1 
Hernández-Rabaza, V., Llorens-Martin, M., Velázquez-Sánchez, C., Ferragud, A., Arcusa, A., Gumus, H. G., et al. (2009). Inhibition of adult hippocampal neurogenesis disrupts contextual learning but spares spatial working memory, long-term conditional rule retention and spatial reversal. Neuroscience 159, 5968. doi: 10.1016/j.neuroscience.2008.11.054

Imayoshi, I., Sakamoto, M., Ohtsuka, T., Takao, K., Miyakawa, T., Yamaguchi, M., et al. (2008). Roles of continuous neurogenesis in the structural and functional integrity of the adult forebrain. Nat. Neurosci. 11, 1153-1161. doi: 10.1038/nn. 2185

Joels, M., Pu, Z., Wiegert, O., Oitzl, M. S., and Krugers, H. J. (2006). Learning under stress: how does it work? Trends Cogn. Sci. 10, 152-158. doi: 10.1016/j.tics.2006. 02.002

Keller, M., Pawluski, J. L., Brock, O., Douhard, Q., and Bakker, J. (2010). The alphafetoprotein knock-out mouse model suggests that parental behavior is sexually differentiated under the influence of prenatal estradiol. Horm. Behav. 57, 434 440. doi: 10.1016/j.yhbeh.2010.01.013

Koehl, M., and Abrous, D. N. (2011). A new chapter in the field of memory: adult hippocampal neurogenesis. Eur. J. Neurosci. 33, 1101-1114. doi: 10.1111/j.14609568.2011.07609.x

Lafenetre, P., Leske, O., Wahle, P., and Heumann, R. (2011). The beneficial effects of physical activity on impaired adult neurogenesis and cognitive performance. Front. Neurosci. 5:51. doi: 10.3389/fnins.2011.00051

Laws, S. C., Carey, S. A., Ferrell, J. M., Bodman, G. J., and Cooper, R. L. (2000). Estrogenic activity of octylphenol, nonylphenol, bisphenol A and methoxychlor in rats. Toxicol. Sci. 54, 154-167. doi: 10.1093/toxsci/54.1.154

Lephart, E. D., Setchell, K. D., Handa, R. J., and Lund, T. D. (2004). Behavioral effects of endocrine-disrupting substances: phytoestrogens. ILAR J. 45, 443-454. doi: 10.1093/ilar.45.4.443

Luine, V. N. (2008). Sex steroids and cognitive function. J. Neuroendocrinol. 20, 866-872. doi: 10.1111/j.1365-2826.2008.01710.x

Marcondes, F. K., Bianchi, F. J., and Tanno, A. P. (2002). Determination of the estrous cycle phases of rats: some helpful considerations. Braz. J. Biol. 62, 609614. doi: 10.1590/s1519-69842002000400008

Martin, S., Jones, M., Simpson, E., and van den Buuse, M. (2003). Impaired spatial reference memory in aromatase-deficient (ArKO) mice. Neuroreport 14, 1979 1982. doi: 10.1097/00001756-200310270-00020

Martini, M., and Valverde, O. (2012). A single episode of maternal deprivation impairs the motivation for cocaine in adolescent mice. Psychopharmacology (Berl) 219, 149-158. doi: 10.1007/s00213-011-2385-2

Martini, M., Pinto, A. X., and Valverde, O. (2014). Estrous cycle and sex affect cocaine-induced behavioural changes in CD1 mice. Psychopharmacology (Berl) doi: 10.1007/s00213-014-3433-5. [Epub ahead of print].

McClure, R. E., Barha, C. K., and Galea, L. A. (2013). 17beta-Estradiol, but not estrone, increases the survival and activation of new neurons in the hippocampus in response to spatial memory in adult female rats. Horm. Behav. 63, 144 157. doi: 10.1016/j.yhbeh.2012.09.011

McEwen, B. (2002). Estrogen actions throughout the brain. Recent Prog. Horm. Res. 57, 357-384. doi: 10.1210/rp.57.1.357

McLean, A. C., Valenzuela, N., Fai, S., and Bennett, S. A. (2012). Performing vaginal lavage, crystal violet staining and vaginal cytological evaluation for mouse estrous cycle staging identification. J. Vis. Exp. 67, e4389. doi: 10.3791/ 4389

Olea, N., and Olea-Serrano, M. F. (1996). Oestrogens and the environment. Eur. J. Cancer Prev. 5, 491-496.

Onishi, B. K., and Xavier, G. F. (2010). Contextual, but not auditory, fear conditioning is disrupted by neurotoxic selective lesion of the basal nucleus of amygdala in rats. Neurobiol. Learn. Mem. 93, 165-174. doi: 10.1016/j.nlm.2009.09.007

Onksen, J. L., Brown, E. J., and Blendy, J. A. (2011). Selective deletion of a cell cycle checkpoint kinase (ATR) reduces neurogenesis and alters responses in rodent models of behavioral affect. Neuropsychopharmacology 36, 960-969. doi: 10. 1038/npp.2010.234

Ormerod, B. K., Lee, T. T., and Galea, L. A. (2004). Estradiol enhances neurogenesis in the dentate gyri of adult male meadow voles by increasing the survival of young granule neurons. Neuroscience 128, 645-654. doi: 10.1016/j.neuroscience. 2004.06.039

OSLO PARIS Convention (OSPAR) Commission. (2002). OSPAR background document on methoxychlor (2004 update). 1-22. Available online at: http://www.ospar.org/documents/dbase/publications/p00147 _background\%20document $\% 20$ on $\% 20$ methoxychlor.pdf
Palanza, P., Gioiosa, L., and Parmigiani, S. (2001a). Social stress in mice: gender differences and effects of estrous cycle and social dominance. Physiol. Behav. 73, 411-420. doi: 10.1016/S0031-9384(01)00494-2

Palanza, P., Morellini, F., Parmigiani, S., and vom Saal, F. S. (1999). Prenatal exposure to endocrine disrupting chemicals: effects on behavioral development. Neurosci. Biobehav. Rev. 23, 1011-1027. doi: 10.1016/s0149-7634(99) 00033-0

Palanza, P., Morellini, F., Parmigiani, S., and vom Saal, F. S. (2002). Ethological methods to study the effects of maternal exposure to estrogenic endocrine disrupters: a study with methoxychlor. Neurotoxicol. Teratol. 24, 55-69. doi: 10. 1016/s0892-0362(01)00191-x

Palanza, P., Parmigiani, S., and vom Saal, F. S. (2001b). Effects of prenatal exposure to low doses of diethylstilbestrol, o,p'DDT and methoxychlor on postnatal growth and neurobehavioral development in male and female mice. Horm. Behav. 40, 252-265. doi: 10.1006/hbeh.2001.1697

Petrik, D., Lagace, D. C., and Eisch, A. J. (2012). The neurogenesis hypothesis of affective and anxiety disorders: are we mistaking the scaffolding for the building? Neuropharmacology 62, 21-34. doi: 10.1016/j.neuropharm.2011.09.003

Porsolt, R. D., Brossard, G., Hautbois, C., and Roux, S. (2001). Rodent models of depression: forced swimming and tail suspension behavioral despair tests in rats and mice. Curr. Protoc. Neurosci. doi: 10.1002/0471142301.ns0810as14

Rapp, P. R., Morrison, J. H., and Roberts, J. A. (2003). Cyclic estrogen replacement improves cognitive function in aged ovariectomized rhesus monkeys. J. Neurosci. 23, 5708-5714.

Revest, J. M., Dupret, D., Koehl, M., Funk-Reiter, C., Grosjean, N., Piazza, P. V., et al. (2009). Adult hippocampal neurogenesis is involved in anxiety-related behaviors. Mol. Psychiatry 14, 959-967. doi: 10.1038/mp.2009.15

Sanderson, D. J., Good, M. A., Skelton, K., Sprengel, R., Seeburg, P. H., Rawlins, J. N., et al. (2009). Enhanced long-term and impaired short-term spatial memory in GluA1 AMPA receptor subunit knockout mice: evidence for a dualprocess memory model. Learn. Mem. 16, 379-386. doi: 10.1101/lm.1339109

Saxe, M. D., Battaglia, F., Wang, J. W., Malleret, G., David, D. J., Monckton, J. E., et al. (2006). Ablation of hippocampal neurogenesis impairs contextual fear conditioning and synaptic plasticity in the dentate gyrus. Proc. Natl. Acad. Sci. U S A 103, 17501-17506. doi: 10.1073/pnas.0607207103

Scharfman, H. E., and Maclusky, N. J. (2005). Similarities between actions of estrogen and BDNF in the hippocampus: coincidence or clue? Trends Neurosci. 28, 79-85. doi: 10.1016/j.tins.2004.12.005

Simpson, J., and Kelly, J. P. (2012). An investigation of whether there are sex differences in certain behavioural and neurochemical parameters in the rat. Behav. Brain Res. 229, 289-300. doi: 10.1016/j.bbr.2011.12.036

Snyder, J. S., Glover, L. R., Sanzone, K. M., Kamhi, J. F., and Cameron, H. A. (2009). The effects of exercise and stress on the survival and maturation of adult-generated granule cells. Hippocampus 19, 898-906. doi: 10.1002/hipo. 20552

Snyder, J. S., Soumier, A., Brewer, M., Pickel, J., and Cameron, H. A. (2011). Adult hippocampal neurogenesis buffers stress responses and depressive behaviour. Nature 476, 458-461. doi: 10.1038/nature10287

Veyrac, A., Gros, A., Bruel-Jungerman, E., Rochefort, C., KleineBorgmann, F. B., Jessberger, S., et al. (2013). Zif268/egr1 gene controls the selection, maturation and functional integration of adult hippocampal newborn neurons by learning. Proc. Natl. Acad. Sci. U S A 110, 7062-7067. doi: 10.1073/pnas.12205 58110

vom Saal, F. S., and Hughes, C. (2005). An extensive new literature concerning lowdose effects of bisphenol A shows the need for a new risk assessment. Environ. Health Perspect. 113, 926-933. doi: 10.1289/ehp.7713

Warner-Schmidt, J. L., Madsen, T. M., and Duman, R. S. (2008). Electroconvulsive seizure restores neurogenesis and hippocampus-dependent fear memory after disruption by irradiation. Eur. J. Neurosci. 27, 1485-1493. doi: 10.1111/j.14609568.2008.06118.x

Watson, R. E. Jr., Wiegand, S. J., Clough, R. W., and Hoffman, G. E. (1986). Use of cryoprotectant to maintain long-term peptide immunoreactivity and tissue morphology. Peptides 7, 155-159. doi: 10.1016/0196-9781(86)90076-8

Welshons, W. V., Nagel, S. C., and vom Saal, F. S. (2006). Large effects from small exposures. III. Endocrine mechanisms mediating effects of bisphenol A at levels of human exposure. Endocrinology 147, S56-S69. doi: 10.1210/en. 2005-1159

Welshons, W. V., Nagel, S. C., Thayer, K. A., Judy, B. M., and Vom Saal, F. S. (1999). Low-dose bioactivity of xenoestrogens in animals: fetal exposure to low doses 
of methoxychlor and other xenoestrogens increases adult prostate size in mice. Toxicol. Ind. Health 15, 12-25. doi: 10.1177/074823379901500103

World Health Organization. (1996). Guidelines for Drinking Quality. Vol 2. Health Criteria and Other Supporting Information. 2nd edition. Geneva: World Health Organization.

WHO (World Health Organization). (2011). Global insecticide use for vector-borne disease control: a 10-year assessment, 2000-2009. 5th Edn. WHO/HTM/NTD/VEM/WHOPES/2011. Available online at: http://whqlibdoc. who.int/publications/2011/9789241502153_eng.pdf Accessed 10 January 2012.

Winocur, G., Wojtowicz, J. M., Sekeres, M., Snyder, J. S., and Wang, S. (2006). Inhibition of neurogenesis interferes with hippocampus-dependent memory function. Hippocampus 16, 296-304. doi: 10.1002/hipo.20163

Yu, C., Tai, F., Zeng, S., and Zhang, X. (2013). Effects of perinatal daidzein exposure on subsequent behavior and central estrogen receptor alpha expression in the adult male mouse. Prog. Neuropsychopharmacol. Biol. Psychiatry 43, 157-167. doi: 10.1016/j.pnpbp.2012.12.015
Conflict of Interest Statement: The authors declare that the research was conducted in the absence of any commercial or financial relationships that could be construed as a potential conflict of interest.

Received: 04 March 2014; accepted: 19 May 2014; published online: 16 June 2014.

Citation: Martini M, Calandreau L, Jouhanneau M, Mhaouty-Kodja $S$ and Keller M (2014) Perinatal exposure to methoxychlor enhances adult cognitive responses and hippocampal neurogenesis in mice. Front. Behav. Neurosci. 8:202. doi: 10.3389/fnbeh.2014.00202

This article was submitted to the journal Frontiers in Behavioral Neuroscience.

Copyright (C) 2014 Martini, Calandreau, Jouhanneau, Mhaouty-Kodja and Keller. This is an open-access article distributed under the terms of the Creative Commons Attribution License (CC BY). The use, distribution or reproduction in other forums is permitted, provided the original author(s) or licensor are credited and that the original publication in this journal is cited, in accordance with accepted academic practice. No use, distribution or reproduction is permitted which does not comply with these terms. 